J OUR N A L OF THE ROYAL SOCIETY OF MEDICINE Volume 97 September 2004

\title{
'Proper to the duty of a chirurgeon': Ambroise Paré and sixteenth century paediatric surgery
}

\author{
A N Williams MSc MRCP J Williams BA RGN
}

J R Soc Med 2004;97:446-449

Ambroise Paré rose from humble origins to become surgeon to four kings of France. Though he is remembered mainly for his work as a military surgeon and for his advocacy of podalic version, his contribution to surgery was far greater than this. ${ }^{1}$ In France his works were a mainstay of surgical practice for 250 years. To illustrate his contributions to paediatric surgery we have translated excerpts from the 1849 facsimile copy of his Oeuvres of $1585,{ }^{2}$ particularly the seventeenth book which deals with the means and artificial devices used to treat those who have natural defects or defects caused by an accident. We also borrow from the posthumous English translation by Thomas Johnson, 1633, edited in the 1950s by Geoffrey Keynes. ${ }^{3}$

Paré's aim was to raise the reputation of surgery to honour and esteem. He wrote:

'Five things are proper to the dutie of a chirurgeon. To take away that which is superfluous, to restore to their places such things as are displaced, to separate those things which are joined together, to joyne that which is divided, and to supply the defects of nature. ${ }^{3}$

From a time when paediatric surgery was still in its infancy and there was little other recorded writing in this area, Paré's works give an insight into what was surgically possible in the sixteenth century.

\section{TO TAKE AWAY THAT WHICH IS SUPERFLUOUS}

In 1545 Paré had proposed pincers for trimming broken bones in hands mutilated by ball and chain; and in the second edition (1552) he recommends the same technique for removal of superfluous digits in the young: 'Fleshy digits can be easily amputated, cutting with a razor all that is superfluous. Bones could be cut with "cutting pincers", . The pincers (Figure 1) could also be used for chronic inflammation of the finger (the concept of infection was unknown at that time).

Child Development Centre, Northampton General Hospital, Northampton NN1 5BD, UK

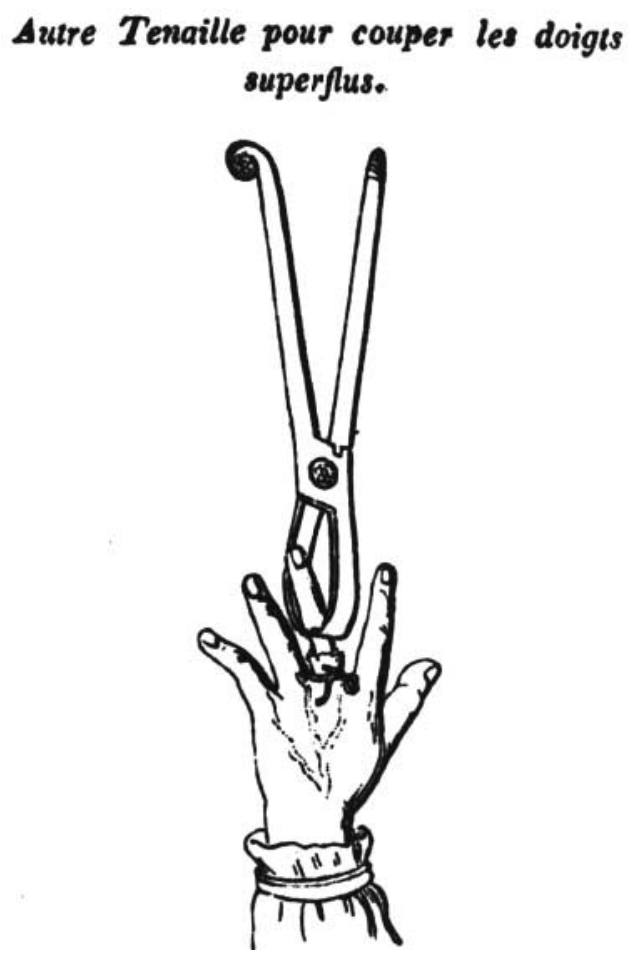

Figure 1 Paré's pincers

\section{TO RESTORE TO THEIR PLACES SUCH THINGS AS ARE DISPLACED}

\section{Club foot}

In a chapter entitled 'The defect in the legs called varus and valgus...' Paré relates his understanding and management of these deformities of the feet. He speculates that the condition is caused prenatally by the mother sitting with her legs crossed or postnatally by the mother holding the child with its feet pressed inward. Following Hippocrates he emphasizes restoration to the natural anatomical position, with bandages in the first instance. However, Paré goes beyond this treatment by devising special orthopaedic boots:

'... one must not make varus and valgus children walk until the joints are well strengthened, so that they do not dislocate. And when one wants to make the children walk, one should split open some high shoes, 
little half boots, and laced up at the front, or fastened by little hooks: they should be of hard leather so as always to keep the bones firmly on the joints, and so that they have to stay there. And the sole must be higher than the side where the malformation will be inclined to turn, in order to force it to turn back to the necessary side'.

The boot (Figure 2), with its wedged sole, was softened with turpentine. Paré does not advocate surgical treatment, and the success rate with his boot is unlikely to have been high. Today, even in the best hands, conservative management of talipes equinovarus through stretching and strapping achieves a lasting correction in only one-third of cases, the remainder requiring surgery. ${ }^{4}$

\section{Scoliosis}

Paré's seventeenth book includes a treatise on scoliosis in which he recognizes the female preponderance. He was the first to describe congenital scoliosis, but in cases of later onset he included among probable causes trauma, poor posture, and in girls the use of bodices and the requirement to curtsey. ${ }^{5}$

For adults with scoliosis he recommended the Hippocratic treatment involving forcible horizontal traction, ${ }^{5}$ but for children he was the first to prescribe iron corsets:

'. . . they should wear fine iron corsets with holes in so that they are not too heavy, and they will be so well fitted and padded that they will not cause any injury. They would be changed often if the invalid does not achieve the three dimensions. And for those girls who grow, it would have to be changed every three months, more or less as necessary: for otherwise, instead of doing good, it would do harm'.

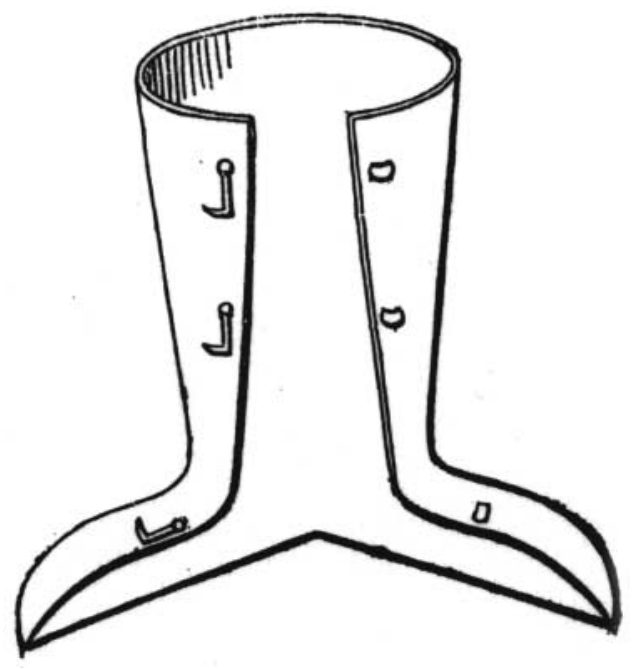

Figure 2 The orthopaedic boot (a)
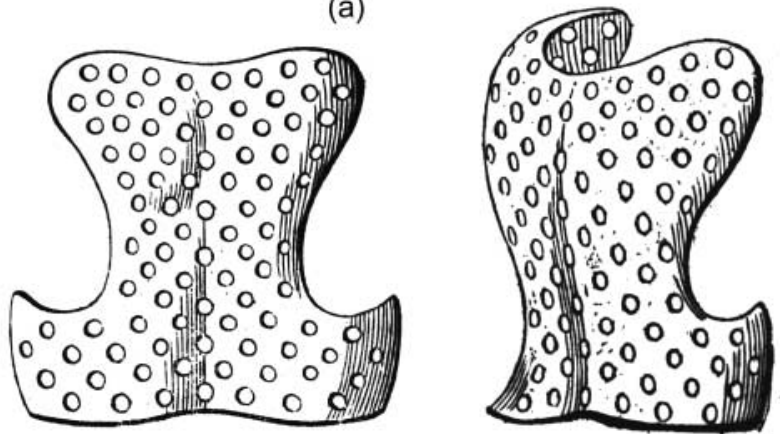

(b)

Figure 3 Front and back plates for scoliosis

\section{Portrait d'vn masque par lequel la veuë est redressée.}

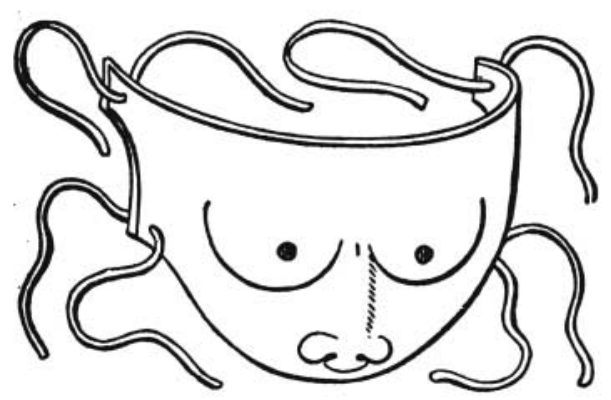

Figure 4 Mask for treatment of strabismus

Paré's corset (Figure 3) remained in use for over a century. In our own time it is well recognized that, if the scoliosis is already severe when diagnosed, bracing will be ineffective. ${ }^{6}$

\section{Dislocation of the hip}

Pare recognized that hip dislocation could be caused not only by external forces but also by defects in the structures of the joints. He does not recommend a specific treatment for children but comments that, if the bones are easily dislocated, they can be 'easily restored without the assistance of a surgeon'.1

\section{Strabismus}

Strabismus (squint) affects $4 \%$ of children under 6 years of age and leads to amblyopia in one-third or more. Paré's speculations on the origin of this condition include positioning the infant's cot in the light and also the child imitating his cross-eyed nurse, and he recommends a face mask be held in place by strings, well fitted to prevent daylight entering through gaps (Figure 4):

'Such a face mask would have only two small holes where the pupils are, to allow light in. This would mean 
Fijure des besicles.

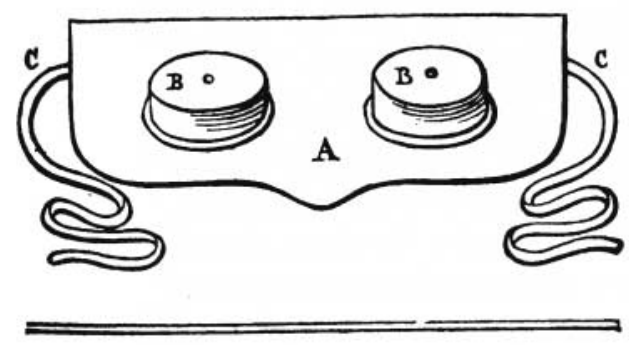

Figure 5 Paré's spectacles for strabismus

that the child only sees light through these holes, would only look straight ahead, so that the eyes would become accustomed to staying straight and still, and this would become the normal habit rather than looking to the side'.

An alternative method used spectacles (Figure 5).

'Instead of this mask, one could similarly make spectacles from horn, which would be moulded onto leather and placed over the eyes. In the middle would be a little hole through which the child would see and therefore correct the problem'.

These were not true innovations in ophthalmology; strabismus masks had been used before. However, in adults Paré was the first to describe the use of glass eyes. $^{7}$

\section{TO SEPARATE THOSE THINGS WHICH ARE JOINED TOGETHER}

In the chapter of the fifteenth book discussing superfluous fingers Paré also deals with fingers fused through accident (usually a burn) or by nature:

'If the surgeon knew that there was little thickness, having only the thickened skin and very little flesh holding them together and attaching them to each other, they could be easily separated with a sharp blade; on the contrary, if they more significantly joined so that the tendons and the nerves were joined together, the surgeon should not touch them'.

\section{TO JOYNE THAT WHICH IS DIVIDED}

\section{Hare lip}

Together with cleft palate, hare lip is the most common congenital abnormality in the head and neck area, with an incidence of about 1 in 7000. Paré's method for repair of simple hare lip is as follows:
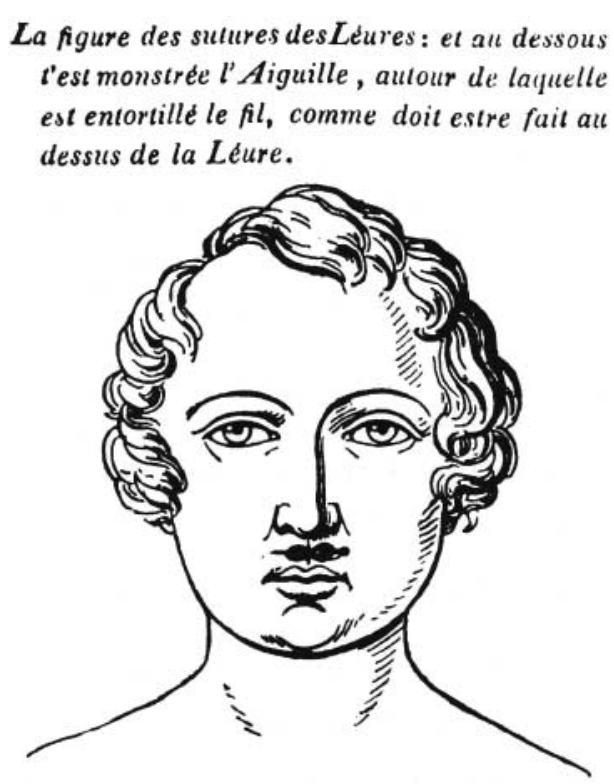

Figure 6 Paré's hare lip repair

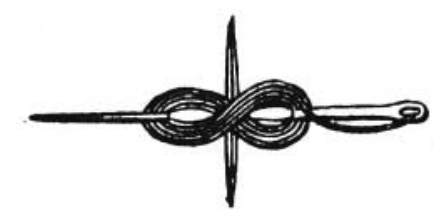

'This method of suturing is used on lips and also necessary for lips split from birth through a failure of the vertical formation. This suturing would have no effect if there was thick hard skin between the lips. Therefore there is a need to cut everything, otherwise there would be no healing. Other methods of suturing are of little use with such wounds, because the areas are mobile, through both chewing and talking. Consequently the thread would cut through the flesh: and, again for this reason, the needles must take in much flesh as in the figure' [Figure 6].

Today hare lip is usually repaired at 3 months of age, with a wide variety of techniques.

Figure d'vne oreille arlificielle.

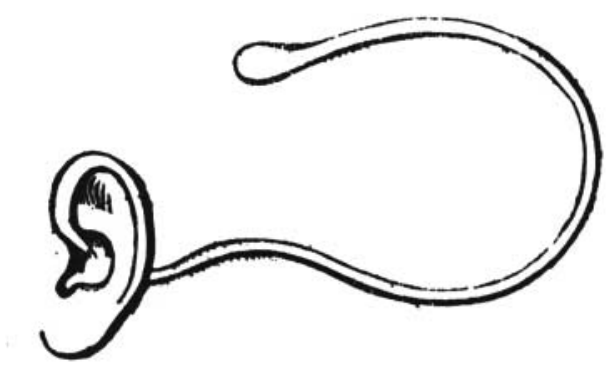

Figure 7 The artificial ear 


\section{TO SUPPLY THE DEFECTS OF NATURE}

\section{Artificial ear}

Paré described an artificial ear for use in managing congenital defects or ears damaged by animal bites or infection:

'... where the ear might have been completely amputated, one would attach an artificial ear made of glued paper or boiled leather shaped with good grace as in the illustration [Figure 7]. And this would be held with straps around the head or the patient would let his hair grow long or wear a skull cap'.

This artificial pinna might have been effective in aiding vertical localization of sound in users with good highfrequency hearing. ${ }^{8}$

\section{Artificial nipple}

Though a strong advocate of breastfeeding, Paré cites Galen's dictum that infants should be breastfed only 'for as long as one knows that the nurse has enough to feed the child as he grows'. He recognized that breastfeeding can be painful, especially when the infant acquires teeth, and to allow continued feeding by a woman with an ulcer he devised a nipple shield made of lead, with small holes for passage of the milk. The inside of the shield is polished to promote healing of the ulcer.

The dangers of exposing infants to lead were not, of course, appreciated in Paré's time.

\section{FINAL DUTY OF A CHIRURGIEN}

Paré's surgical practice does not end with the death of his patient. In his book How to Make Reports he lists the features he finds useful in distinguishing between natural and suspicious death:

'For if the infant were in good health before, if he were not froward or crying, if his mouth and nosethrills now being dead, be moystned or bedewed with a certaine foame, if his face be not pale but of a Violet and purple colour: if when the body is opened the Lungs be found swolne and puffed up, as it were with certain vaporous foame and all the other entralls sound, it is a token that the infant was stifled, smothered or strangled by some outward violence'.

Nevertheless, in his practice Paré records the history and necropsy of an infant who had died unexpectedly in whom he was unable to determine a cause of death. He concluded that it was due to teething. Later Paré counsels that when a pregnant woman dies the necropsy should always include the fetus, 'for he meriteth farre greater punishment, who hath killed a child perfectly shaped, and made in all the members: that is he which hath killed a live childe, than he which hath killed an embryon, that is a certaine concretion of the spermaticke body' ${ }^{3}$

\section{CONCLUSION}

Many surgical subspecialties regard Paré as their founding father. The written works are a monument to his integrity, honesty and courage in dealing with cases that even today would be challenging. It is extraordinary that, in an era before Harvey, anaesthesia, and the understanding of sepsis, Paré was able to practise such a wide range of treatments with a measure of success.

Acknowledgement We thank Dr Michelle Dominic and Dr Margaret Holloway for advice and the Postgraduate Library, Northampton General Hospital and the Centre for Medicine, University of Birmingham, for support.

\section{REFERENCES}

1 Dunn PM. Ambroise Paré (1510-1590): surgeon and obstetrician of the Renaissance. Arch Dis Child 1994;71:F231-2

2 Paré A. Oeuvres Complètes. Geneva: Slatkine, 1970

3 Keynes G. The Apologie and Treatise of Ambroise Paré. London: Falcon Educational, 1951

4 Fixsen J, Lloyd-Roberts G. The Foot in Childhood. London: Churchill Livingstone, 1988

5 Moe J. Historical aspects of scoliosis. In: Bradford DS, Lonstein JE, Moe JH, Ogilvie JW, Winter RB, eds. Moe's Textbook of Scoliosis and Other Spinal Deformities. Philadelphia: WB Saunders, 1987:I

6 Le Vay. The History of Orthopaedics. Carnforth: Parthenon, 1990

7 Edwards DD. Ophthalmology in the Middle Ages and Renaissance. In: Albert DM, Edwards DD, eds. The History of Ophthalmology. Oxford: Blackwell Science, 1996:44

8 Byrne D, Sinclair S, Noble W. Open earmold fittings for improving aided auditory localization for sensorineural hearing losses with good high-frequency hearing. Ear Hear 1998;19:62-71 